\title{
Reflective Practioner
}

\section{Sathiadas.MG}

Medicine is scientifically complex, constantly changing field and is a life long journey. It has positive, fulfilling experience and in some situations becomes uncertain and emotionally intense. Reflecting on these experiences is vital to personal wellbeing and development, thereby improves the quality of patient care. (1) The Academy of Medical Royal Colleges, UK define reflective practice as 'the process whereby an individual thinks analytically about anything relating to their professional practice with the intention of gaining insight and using the lessons learned to maintain good practice or make improvements where possible. (2)

There is a strong public interest in doctors for being able to reflect in an open and honest way. Hence reflection should empower students and doctors to demonstrate insight by identifying actions to help learning, improvement of practice, develop a greater insight and self-awareness. Reflection will help to improve quality and patient safety as well.

Reflection is personal and there is no one way to reflect. A variety of tools are available to support structured thinking that help to focus on the quality of reflections. The approach taken to reflective practice may be influenced by the nature and scope of individual practice, and personal style of learning. (3) Thinking should be structured to capture, analyse and learn from the experience. A range of different experiences can be reflected on, including clinical events or interactions, complaints or compliments and feedback, reading a research article, attending a meeting, having a conversation with a colleague or patient, team debriefs, or exploring a feeling or emotional reaction. (4)

Similar to self-reflection, group or team reflection is encouraged especially when complex issues are encountered and also to effect change across the health systems. All members of the healthcare team should have opportunities to reflect on and discuss what has happened openly and honestly when things go wrong in a supportive and confidential setting. This is professional duty of candour. Medical students are expected to follow similar advice in achieving good medical practice. Time should be made available, both for self-reflection, and to reflect in groups. Supervisors and appraisers also need time to facilitate reflection especially for students and trainee doctors.

Methods of reflection are numerous. The What? So what? Now what? Framework is one example to structure reflections. What? Focuses on thoughts at the time of an experience. So what? Involves considering the significance of what happened as well as the values and feelings at the time. Now what? Looks at the processes and opportunities that can help learning from the experience and identifying future actions, reflection on those actions, and how to use these to develop further.

Professor Graham Gibbs published about the reflective Cycle in his 1988 book "Learning by Doing." It is useful to help learn from situations that they experience regularly, especially when these don't go well. (5) There are five stages in the cycle: description, feelings, evaluation, conclusions and action. (5)

The reflection becomes a successful learning curve when the learner is able to analyse the experience with insight, relate what was learnt from the experience based on the standard practice and theory, indicates how the experience should improve, is able to plan short and long term learning goals, identify personal strategies to achieve the goal and also demonstrate the personal growth over time. (6)

Documentation of the experience and reflections are needed for medical students and trainee doctors. When documenting experiences confidentiality should be maintained. One must understand that reporting a critical incident is different from reflective notes. Hence anonymity 
of patient details must be practiced in reflections. Where there are concerns or questions about the content of reflection, the advice of a supervisor or appraiser should be sought as to whether the information is appropriate. The purpose of the reflection is to indicate learning and, where appropriate, future plans. (1)

"Reflective practice is a dialogue of thinking and doing through which I become more skilful."

\section{References:}

- Donald Schon

1. Andrew Grant, Judy McKimm and Fiona Murphy. Developing reflective practice: A guide for medical students, doctors and teachers. Wiley Blackwell, 2017.

2. Academy ofMedical Royal Colleges/COPMeD. Reflective practice toolkit, 2018. www. aomrc.org.uk/wp-content/uploads/2018/08/
MCJ15414-Academy- ReflectivePracticeMain-v3.pd

3. David Kolb. Experiential Learning: Experience as the Source of Learning and Development. Prentice-Hall, 198

4. Academy of Medical Royal Colleges/COPMeD. Reflective practice toolkit, 2018. www. aomrc.org.uk/wp-content/uploads/2018/08/ MCJ15414-Academy- Reflective PracticeMain-v3.pdf

5. Gibbs, G. (1988). Learning by Doing: A Guide to Teaching and Learning Methods. Oxford: Oxford Further Education Unit

6. Muir, F., Scott, M., McConville, K., Watson, K., Behbehani, K., \& Sukkar, F. 2014. Taking the learning beyond the individual: how reflection informs change in practice. International Journal of Medical Education. 5:24-30. 